\title{
Brain-Computer Interfaces for upper limb motor rehabilitation of stroke patients
}

\section{Interfaces Cerebro-Computadora para la Rehabilitación Motora de Miembro Superior de Pacientes con Enfermedad Vascular Cerebral}

\author{
R. I. Carino-Escobar, J. Cantillo-Negrete
}

Instituto Nacional de Rehabilitación Luis Guillermo Ibarra Ibarra

\begin{abstract}
Brain-Computer Interfaces (BCI) decode users' intentions from the central nervous system and could be applied for upper limb motor rehabilitation of patients that have suffered stroke, one of the main causes of disability worldwide. Despite that research groups have reported the efficacy of these systems, a consensus has not yet been reached regarding their true potential. For this reason, a review of up-to-date assessments of BCI for upper limb stroke rehabilitation is presented from the perspective of analyzing common and different design variables presented across studies. Clinical and pilot studies with a control group were included in the review. Most BCI interventions assessments were performed with robotic assistive devices as feedback, followed by neuromuscular electrical stimulation (NMES) and visual feedbacks. Compared to other experimental interventions, the effects of a BCI intervention have been reported in a low number of patients. In addition, high variability between studies' designs such as stroke etiology and interventions' duration, do not allow to assess the potential of BCI for stroke rehabilitation. However, a trend towards significant rehabilitation outcomes with BCI systems can be highlighted, encouraging research groups to better coordinate in order to make valuable contributions to the field.
\end{abstract}

ABSTRACT

KEYwORDS: BMI; NMES; hemiparesis; neurofeedback; neuroplasticity 


\section{RESUMEN}

Las interfaces cerebro-computadora (BCI) decodifican del sistema nervioso central las intenciones de los usuarios, y pueden ser aplicadas para la rehabilitación motora del miembro superior de pacientes con enfermedad vascular cerebral (EVC), una de las principales causas de discapacidad a nivel mundial. A pesar de que diversos grupos han reportado la eficacia de estos sistemas, no se ha logrado un consenso sobre su verdadero potencial. Por esta razón, una revisión de la evaluación reciente de las BCI para rehabilitación del miembro superior en la EVC es presentado desde la perspectiva de analizar diferencias y similitudes entre las variables reportadas en los estudios. En la esta revisión se incluyeron estudios clínicos y pilotos con un grupo control. La mayor parte de los estudios utilizaron sistemas robóticos como retroalimentación, seguido por estimulación eléctrica neuromuscular y retroalimentación visual. En comparación con otras terapias experimentales, los efectos de intervenciones con BCI se han reportado en pocos pacientes. Además, la alta variabilidad en el diseño de los estudios, como la etiología de la EVC y la duración de las intervenciones, no permiten comparar los efectos de las terapias BCI. Sin embargo, se puede resaltar una tendencia hacia recuperaciones motoras significativas con BCI, motivando a grupos de investigación a coordinarse de mejor forma para continuar realizando contribuciones al campo.

PALABRAS CLAVE: BMI; estimulación eléctrica; hemiparesia; retroalimentación; neuroplasticidad

\section{Correspondencia}

DESTINATARIO: Jessica Cantillo Negrete INSTITUCIÓN: Instituto Nacional de Rehabilitación Luis Guillermo Ibarra Ibarra DIRECCIÓN: Av. México Xochimilco \#289, Col. Arenal de Guadalupe, C. P. 14389, Alcaldía Tlalpan, Ciudad de México, México CORREO ELECTRÓNICO: jcantillo@inr.gob.mx

\section{Fecha de recepción:}

15 de junio de 2019

Fecha de aceptación:

12 de enero de 2020 


\section{INTRODUCTION}

Brain-Computer Interfaces (BCI) are systems that decode users' intentions from the central nervous system in order to control external devices ${ }^{[1]}$. Applications for BCI include entertaining [2], neuromarketing [3], environmental control [4], communication [5], and treatment of motor-related diseases such as spinal cord injury and stroke [6] [7]. BCI were initially conceived for the later application, since they can provide an external communication pathway between motor impaired users and assistive devices. Particularly, during the last 10 years, BCI interventions have been studied as therapies aimed to improve upper limb motor recovery of stroke patients ${ }^{[8]}$. One of the main reasons for the growing interest in BCI for stroke rehabilitation is that patients can still control a BCI despite damaged brain tissue. In addition, since stroke is one of the main causes of motor disability worldwide, the research of new therapies is a priority in order to decrease the burden in healthcare systems ${ }^{[9]}$.

For these reasons, several research groups have focused in the development of BCI technology, and its assessment for upper limb rehabilitation of stroke patients. However, a consensus regarding the efficacy of BCI for stroke rehabilitation has yet to be reached.

One of the reasons for this is that different variables related to the experimental design of reported studies, could affect rehabilitation outcomes of the patients. Therefore, this study aims to provide a comprehensive review of up-to-date literature related to BCI applied to upper limb motor rehabilitation of stroke patients, with the focus of analyzing study designs and outcomes. Although other reviews regarding BCI for neurorehabilitation have been reported ${ }^{[10]}$ [11], to the authors' knowledge a review that assesses these experimental design variables is still needed. This is addressed by first explaining theoretical fundaments, trends within the most important studies published and variables related to study design.

\section{Stroke}

Stroke is caused by a blockage (ischemic), or rupture (hemorrhagic) of blood vessels within the brain. This causes damage within the corticospinal tract of the affected hemisphere producing hemiparesis, paralysis of the body's hemisphere contralateral to the lesion ${ }^{[12]}$. Stroke can also produce aphasia defined as a communication disorder acquired due to brain damage that affects the ability to understand, produce and use language ${ }^{[13]}$. Loss of vision and behavior changes can also be presented in stroke survivors ${ }^{[12]}$. Stroke sequalae is most likely caused by size and location of the lesion, making each patient's stroke unique regarding the extent of the produced disability ${ }^{[12]}$. However, motor impairment produced by hemiparesis is one of the most significant sources of disability worldwide, with an estimated incidence of 795,000 new cases per year, and a prevalence in $2.5 \%$ of the United States population ${ }^{[9]}$. Stroke burden has mainly increased in low and middle-income countries ${ }^{[9]}$, including Mexico, where incidence has been estimated in 339 new cases for each 100,000 inhabitants per year, with a prevalence of 18.2 for every 1000 people older than 60 years ${ }^{[14]}$. Therefore, approximately 200,000 people live with stroke sequalae in Mexico, and this number will rise as population with more than 60 years increases. The rise of stroke burden in global healthcare systems and, the low motor recovery rates of patients with severe initial motor impairment, highlight the importance of researching techniques for complementing conventional treatment for stroke.

\section{Stroke Rehabilitation}

After the initial symptoms of stroke, patients need urgent medical attention. This attention must be comprised by diagnosis through computed tomography (CT) or magnetic resonance (MR) images. After diagnosis confirmation, acute stroke management can include endovascular and intravenous thrombolytic therapies, and management of blood pressure, glucose, temperature and oxygen ${ }^{[15]}$. Once the patient's 
condition is stable, treatment mainly relies in rehabilitation therapies. Some guidelines for stroke treatment include interdisciplinary approaches focusing in: dysphagia and nutritional management, upper and lower extremity rehabilitation, communication and cognitive enhancement therapies, and management of secondary complications ${ }^{[16]}$. Specifically, upper limb standard rehabilitation is focused in providing occupational and physical therapy during subacute (at most 1 year after the stroke onset) and chronic (more than a year after onset) stages of stroke ${ }^{[17]}$. Occupational therapy is comprised by repetitive, progressive and targeted specific oriented exercises, aimed at performing activities of daily living ${ }^{[16]}$. Physical therapy is comprised by the application of physical agents such as water and temperature for increasing upper limb function and decreasing excessive muscle tone caused by spasticity ${ }^{[16]}$. Even if standard rehabilitation is provided to stroke patients, it is estimated that only 35\% of patients with severe initial impairment will recover enough upper limb motor function to use their paralyzed limb for daily activities ${ }^{[17]}$. Therefore, other therapies besides standard treatment have also been evaluated for upper limb motor rehabilitation. Some examples include mirror therapy, transcranial magnetic stimulation (TMS), transcranial direct current stimulation (tDCS), virtual reality and motor imagery. One of the therapies that has achieved enough evidence to be regarded as a promising complement to standard therapy, is rehabilitation using robotic assistive devices ${ }^{[18]}$. Upper limb robotic interventions have the advantage of increasing the number of therapies provided by healthcare systems, which number of standard sessions and session's time per patient have been reduced due to the increasing number of patients requiring stroke treatment ${ }^{[19]}$. Several robotic systems such as the MIT MANUS ${ }^{[20]}$, Amadeo ${ }^{[21]}$ and ARMEO ${ }^{[22]}$ have been developed, and their effects are still being reported in stroke patients' upper limb rehabilitation. BCI are another potential therapy that can be coupled to robotic assistive devices for stroke rehabilitation.
The main goal of all therapies, standard or experimental, is neural plasticity enhancement. Neural plasticity is the ability of the brain of reorganizing and is presented during learning and recovery after brain damage ${ }^{[17]}$. In order to measure patients' upper limb disability, several scales are currently used in the clinical environment. Some of the most used are the FuglMeyer Assessment for the Upper Extremity (FMA-UE), which assigns a score between 0-66 points, with a higher score suggesting a lower impairment [23]. Another widely used clinical score is the Arm Research Arm Test (ARAT), this scale assigns a 0-57 score, als with a higher score suggesting lower upper limb impairment ${ }^{[24]}$. Unlike the FMA-UE, for the ARAT, special items are needed to perform the test, such as wooden blocks of specific dimensions and sizes. Both FMA-UE and ARAT have shown to have similar scores for assessing upper limb motor impairment in stroke patients, however, they are not regarded as equivalent [25]. Other clinical assessments of stroke upper limb impairment are the Stroke Impact Scale (SIS) ${ }^{[26]}$, the 9-Hole Peg Test (9HPT) ${ }^{[19]}$, European Stroke Scale score (ESS) [27], Goal Attainment Scaling (GAS) [28], Motor Activity Log (MAL) ${ }^{[29]}$, Motor Assessment Scale (MAS) [30], Stroke Impairment Assessment set (SIAS) [31], Modified Barthel Index (MBI) ${ }^{[32]}$, Medical Research Council muscle strength scoring system (MRC) [33], Jebsen Hand Function Test (JHFT) ${ }^{[34]}$ and, the National Institutes of Health Stroke Scale (NIHSS) ${ }^{[35]}$. Physiological based evaluations have also been reported for assessment of upper limb hand disability, such as quantitative EEG [36], dynamometry, Transcranial Magnetic Stimulation (TMS) ${ }^{[37]}$ and range of movement (ROM).

\section{Brain-Computer Interfaces}

$\mathrm{BCI}$ are systems that translate brain signals into commands to control external devices ${ }^{[1]}$. Brain signals can be acquired by means of different 207 techniques as

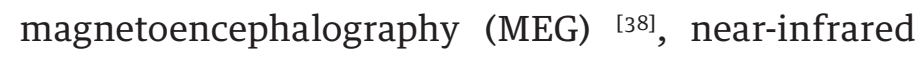
spectroscopy (NIRS) ${ }^{[39]}$, electrocorticography (ECoG) 
${ }^{[40]}$, local field potentials (LFP) recordings ${ }^{[41]}$, electroencephalography (EEG) ${ }^{[42]}$, among others. MEG has the best compromise between time and spatial resolution, however, it also the most complex acquisition modality for $\mathrm{BCI}$ and the least available for practical applications. To the authors' knowledge, in Mexico, no public health care institution has MEG devices. NIRS is a noninvasive technique but has poor time resolution. While ECoG and LFP are invasive techniques, it means that a neurosurgery needs to be performed to implant microelectrodes in the brain tissue. The disadvantage of these invasive methods is that the quality of the signal decreases in long-term recordings, making time and spatial resolution unfeasible for BCI applications in a matter of months ${ }^{[43]}$. EEG has a good time resolution, and poor spatial resolution compared to MEG and invasive acquisition methods. But since the electrodes are placed over scalp, it has a relatively low cost making it highly accessible and acceptable by patients. In almost all public healthcare institutions in Mexico there is a device for EEG recording. Hence, EEG is the most suitable technique to implement acquisition of brain signals in BCIs. In order to translate brain signals into control commands, a processing algorithm is required, comprised by preprocessing, feature extraction and classification of the signal. In the stateof-art literature, there are several methods that have been tested to process EEG signals for BCI [44] [45] [46]. Indeed, most published papers in the subject of BCI are related to new processing algorithms tested offline. But, the implementation of a close-loop BCI requires algorithms running in online applications. Another stage of BCI is feedback, which comprises external devices, this stage depends on the goal of the BCI and it can be divided in three different applications: communication, substitution and rehabilitation. In the first, the external device can be a computer monitor; in the second, a hand prosthetic or a wheelchair; and in the third, visual feedback displayed in a screen, a robotic hand orthosis, augmented virtual reality, or neuromuscular electrical stimulation (NMES).
Figure 1 shows a depiction of a BCI system's stages. The objective of BCIs applied for upper limb rehabilitation is to excite the peripheral nervous system in order to facilitate neural plasticity ${ }^{[47]}$. This closed-loop communication allows users to control, arm, wrists or fingers, with their movement attempt (MA) or motor imagery (MI), even if they are paralyzed due to hemiparesis. Using MI, stroke patients can still elicit similar cortical activations as the ones observed due to movements, as demonstrated by studies that used high resolution imaging techniques ${ }^{[48]}{ }^{[49]}$. A motor Imagery Questionnaire has been proposed to indirectly measure a subject's ability to perform MI (KVIQ) ${ }^{[50]}$.

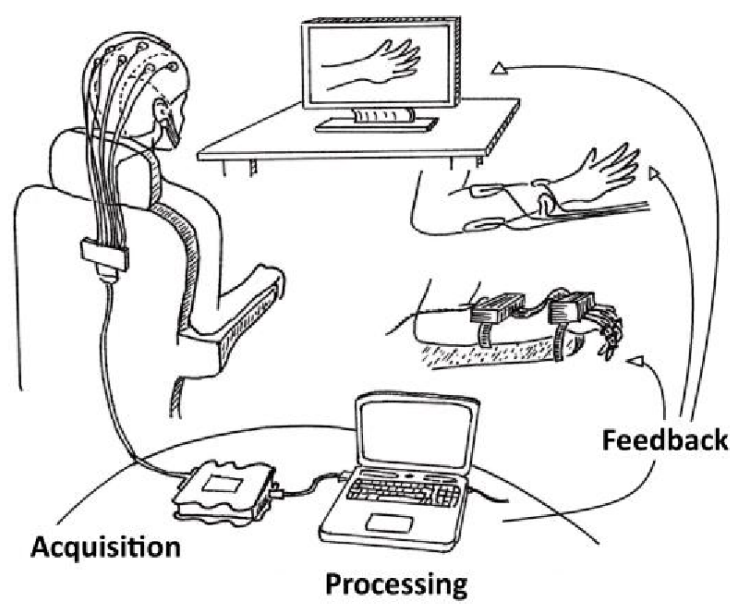

FIGURE 1. Stages of a BCl system. The three main types of feedbacks used for stroke patients' upper limb rehabilitation are illustrated.

Here, a review of up-to-date literature regarding BCI applied for upper limb stroke rehabilitation was performed by classifying studies that used different types of BCI feedback into 3 categories: visual, robotic devices and NMES. The research was performed in PUBMED, Web of Science, Sciencedirect, Spingerlink, IOPscience, Taylor \& Francis, Hindawi and IEEE Xplore, databases. In order for studies to be included in the current review, tests with feedback provided to patients had to be reported. The main objective of selected studies had to be the assessing of a close-loop BCI based on noninva- 


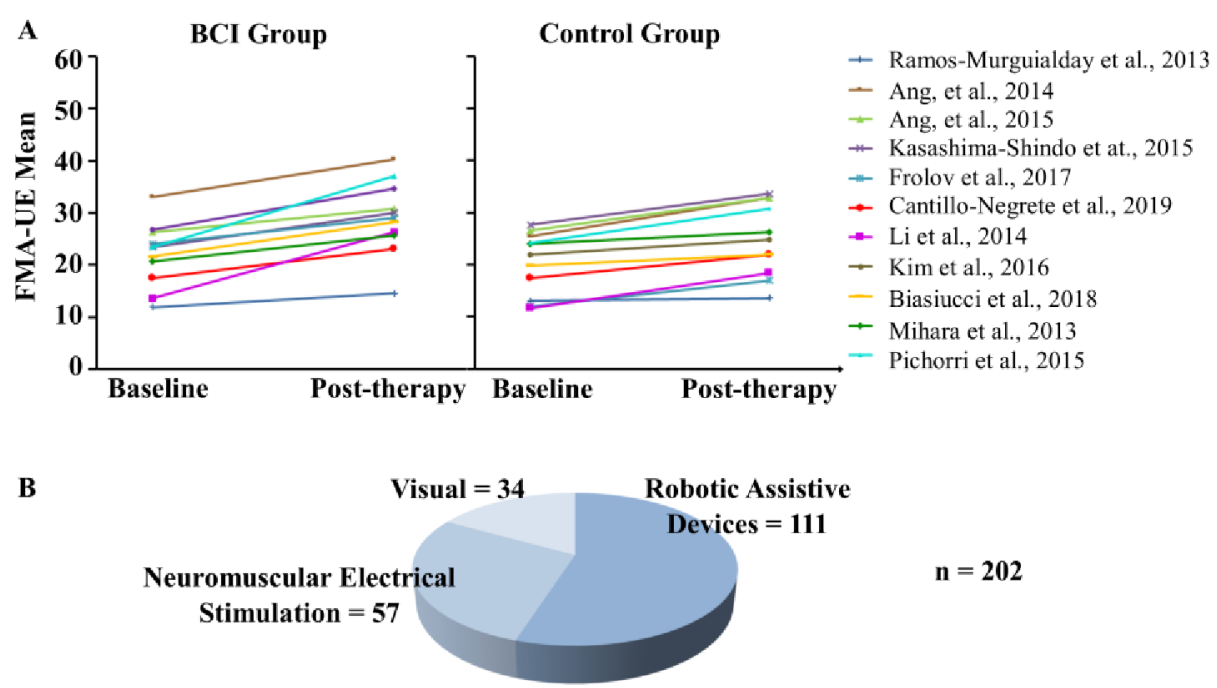

FIGURE 2. A) Baseline and post-therapy Fugl-Meyer Assessment for Upper Extremity measured in all the included studies.

B) Number of stroke patients that have received upper limb BCI therapy for stroke classified by feedback type.

sive techniques for upper limb stroke neurorehabilitation. Studies designs had to include a control group. Therefore, case studies and case series studies were not included, while clinical studies, and controlled pilot studies were included in the review.

\section{BCI with robotic feedback}

Therapies with robotic assistive devices have proven effective for stroke patients' upper limb rehabilitation. Therefore, several research groups have combined these devices with BCI, allowing users to control an exoskeleton or orthosis which provide passive movement to the fingers, wrist or arm of patients using MI or MA. Reported robotic assistive devices combined with BCI for stroke rehabilitation vary largely in complexity and degrees of freedom. One of these device types are hand robotic orthosis that provide finger flexion and extension of stroke patients' paralyzed fingers. Such devices were reported by Kasashima-Shindo et al. in a BCI intervention using a simple design with a motordriven hand orthosis which extends patients' paralyzed fingers ${ }^{[51]}$. Ramos-Murguialday et al. assessed the effects of a BCI coupled to hand robotic orthosis, which also provided finger flexion and extension passive movements, with an orthosis that was fixed to a larger structure ${ }^{[7]}$. Carino-Escobar et al. reported the preliminary results of the effects of an intervention with a 3D-printed robotic hand orthosis, that allowed stroke patients to grasp a baseball placed in front of them using their MA ${ }^{[52]}$. Orthosis or exoskeletons that provide passive movement to the wrist have also been combined with BCI for stroke rehabilitation assessment by Ang et al. using a robotic knob actuator, that allowed patients to receive passive movement simulating the opening of a door knob [53]. Other robotic devices provide movement to patients' arms, such as the MITManus robot exoskeleton. This device has been used as BCI feedback in several studies which assessed BCI interventions in stroke patients, for example, in the studies by Ang et al. ${ }^{[15]}{ }^{[54]}$ and by Varkúti et al. ${ }^{[55]}$. Table 1 shows details of studies which BCI systems' feedbacks were comprised by robotic assistive devices.

\section{BCI WITH NEUROMUSCULAR ELECTRICAL}

\section{Stimulation Feedback}

Similar to robotic assistive devices, neuromuscular electrical stimulation (NMES) has been evaluated by different research groups for stroke patients' upper limb rehabilitation. For NMES application, surface or 
implanted electrodes over the muscle motor points or nerves that innervate targeted muscles are used with a stimulation frequency between 12 and $50 \mathrm{~Hz}$. Strength of muscle contraction can be modulated by varying either pulse amplitude (0-100 mA) or width (0-300 $\mu \mathrm{s})$ ${ }^{[56] . ~ N M E S ~ c a n ~ b e ~ a p p l i e d ~ i n ~ d i f f e r e n t ~ m u s c l e s, ~ d e p e n d-~}$ ing on the number of channels, and type of movement targeted within a patients' paralyzed upper limb. For example, BCI feedback reported by Kim et al. was comprised by the activation of wrist extensor muscles ${ }^{[57]}$. Another work by Biasiucci et al. used NMES to elicit finger and wrists extension ${ }^{[58]}$. The details of studies that apply NMES as BCI feedback for upper limb stroke rehabilitation can be observed in Table 1 .

\section{BCI with visual feedback}

Some studies have reported upper limb motor recovery outcomes in stroke patients after a BCI intervention with exclusively visual feedbacks. Visual feedback has been hypothesized to have the potential of reinforcing motor learning by activating the mirror neuron system [59]. Visual feedbacks reported among studies are heterogeneous, for example, Mihara et al. reported a NIRS-based BCI that showed MI-related hemoglobin signals to patients by displaying them as a vertical bar in a computer monitor during BCI therapy ${ }^{[60]}$. Pichiorri et al. developed BCI provided visual feedback using a virtual hand displayed in the same location as patients' actual hands ${ }^{[61]}$. A summarized description and outcomes of these studies is shown in Table 1.

\section{DISCUSSION}

A total of 14 studies, including 202 patients, were identified in the literature complying with the inclusion criteria for this review [7] [51] [53] [54] [57] [58] [60] [61] [62] [63] [64] [65] [66] ${ }^{[67]}$. This number of patients is lower than the evidence reported in therapies recommended by the Union of EuropeanMedicalSpecialistsPhysicaland Rehabilitation Medicine section for upper limb stroke rehabilitation, such as Constrained-Induced Movement Therapy (CMIT), mirror therapy, and robotic-assistive therapy
[68]. There are 51 controlled trials and 1784 patients reported for CIMT [69], 15 studies which included 392 patients for mirror therapy ${ }^{[70]}$, and 44 controlled trials encompassing 1362 patients for robotic assistive devices. Therefore, this implies that more studies which provide evidence of the effects of BCI therapies for stroke upper limb rehabilitation are still needed, in order to assess the feasibility of these systems and be included within clinical therapy guidelines.

After stratification of the revised studies based in the type of feedback, most of the studies reported the use of robotic assistive devices ( $n=7)$, followed by studies using NMES ( $n=4)$, and visual feedback $(n=3)$, as shown in Figure 2B. The number of patients included in each subgroup also reflected this tendency with 111 patients included in studies with robot therapy, 57 with NMES, and 34 with visual feedback. An explanation for the higher number of studies and patients with robotic feedback could be that robotic devices have been regarded as safe and have potential for enhancing, albeit in a small degree, upper limb rehabilitation in stroke, as concluded by Bertani et al. ${ }^{[18]}$. On the other hand, NMES for upper limb stroke rehabilitation has been assessed in 8 trials encompassing 192 participants, and although a potential as a therapy was recognized, more studies are needed for confirming these observations ${ }^{[71]}$. Therefore, it could be suggested that robotic assistive devices are a more appealable choice for BCI feedback that NMES, at least until more evidence is provided. Visual feedback is the less used BCI feedback modality in the revised upper limb stroke studies. It is likely that the reason for this is that it has been reported that visual feedback produces less pronounced cortical activity in the motor cortex, compared to somatosensory stimulation, such as passive movement provided by robotic assistive devices and

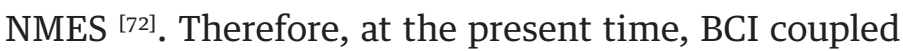
to robotic assistive devices provide the highest evidence of the effects of BCI systems for upper limb stroke rehabilitation. 
TABLE 1. Features and outcomes of the included studies for BCl for upper limb rehabilitation of stroke patients. $\left.{ }^{*}\right)$ Preliminary results published in ${ }^{[52]}$.

\begin{tabular}{|c|c|c|c|c|c|c|c|}
\hline \multicolumn{8}{|c|}{ Robotic Orthosis } \\
\hline Authors & $\begin{array}{l}\text { Stroke } \\
\text { Type }\end{array}$ & Chronicity & $\begin{array}{c}\text { BCI } \\
\text { Group (n) }\end{array}$ & $\begin{array}{c}\text { Control } \\
\text { Group (n) }\end{array}$ & $\begin{array}{c}\text { Intervention } \\
\text { Duration }\end{array}$ & $\begin{array}{l}\text { Outcome } \\
\text { Measure }\end{array}$ & $\begin{array}{c}\text { Improvement } \\
\text { (FMA-UE) }\end{array}$ \\
\hline $\begin{array}{l}\text { Ramos- } \\
\text { Murguialday } \\
\text { et al., } 2013\end{array}$ & No data & Chronic & MI (16) & $\operatorname{Sham}_{(16)}$ & $\begin{array}{c}4 \mathrm{w} \\
(5 \mathrm{~d} / \mathrm{w}, 60 \mathrm{~min} / \mathrm{d})\end{array}$ & $\begin{array}{c}\text { FMA-UE, } \\
\text { GAS, MAL, MAS }\end{array}$ & $\begin{array}{c}\Delta \mathrm{BCI}=2.7 \\
\Delta \text { Control }=0.5\end{array}$ \\
\hline $\begin{array}{l}\text { Ono } \\
\text { et al., } 2014\end{array}$ & No data & Chronic & MI (6) & Visual feedback & $12-20 \mathrm{~d}, 60 \mathrm{~min} / \mathrm{d}$ & $\begin{array}{c}\text { SIAS, } \\
\text { EMG, qEEG }\end{array}$ & No data \\
\hline $\begin{array}{l}\text { Ang, } \\
\text { et al., } 2014\end{array}$ & $\begin{array}{l}\text { Ischemic and } \\
\text { Hemorrhagic }\end{array}$ & Chronic & MI (6) & $\begin{array}{c}\underset{(8)}{\text { Haptic knob }} \\
\underset{(7)}{\text { Standard therapy }}\end{array}$ & $\begin{array}{c}6 \mathrm{w} \\
(3 \mathrm{~d} / \mathrm{w}, 90 \mathrm{~min} / \mathrm{d})\end{array}$ & FMA-UE & $\begin{array}{c}\Delta \mathrm{BCI}=7.2 \\
\Delta \text { Control1 }=7.3 \\
\Delta \text { Control2 }=4.9\end{array}$ \\
\hline $\begin{array}{l}\text { Ang, } \\
\text { et al., } 2015\end{array}$ & $\begin{array}{l}\text { Ischemic and } \\
\text { Hemorrhagic }\end{array}$ & Chronic & MI (11) & $\underset{(14)}{\text { MIT-Manus }}$ & $\begin{array}{c}4 \mathrm{w} \\
(4 \mathrm{~d} / \mathrm{w}, 60 \mathrm{~min} / \mathrm{d})\end{array}$ & FMA-UE & $\begin{array}{c}\Delta \mathrm{BCI}=4.5 \\
\Delta \text { Control }=6.3\end{array}$ \\
\hline $\begin{array}{l}\text { Kasashima-Shindo } \\
\text { et at., } 2015\end{array}$ & $\begin{array}{l}\text { Ischemic and } \\
\text { Hemorrhagic }\end{array}$ & Chronic & MI (7) & $\underset{(11)}{\mathrm{MI}+\mathrm{tDCS}}$ & $\begin{array}{c}2 \mathrm{w} \\
(5 \mathrm{~d} / \mathrm{w}, 45 \mathrm{~min} / \mathrm{d})\end{array}$ & FMA-UE & $\begin{array}{c}\Delta \mathrm{BCI}=6.6 \\
\Delta \text { Control }=6.0\end{array}$ \\
\hline $\begin{array}{l}\text { Frolov } \\
\text { et al., } 2017\end{array}$ & $\begin{array}{l}\text { Ischemic and } \\
\text { Hemorrhagic }\end{array}$ & $\begin{array}{l}\text { Subacute } \\
\text { and chronic }\end{array}$ & MI (55) & $\underset{(19)}{\operatorname{Sham}_{(19}}$ & $\begin{array}{c}2 \mathrm{w} \\
(5 \mathrm{~d} / \mathrm{w}, 30 \mathrm{~min} / \mathrm{d})\end{array}$ & FMA-UE, ARAT & $\begin{array}{c}\Delta \mathrm{BCI}=5.0 \\
\Delta \text { Control }=5.0\end{array}$ \\
\hline $\begin{array}{l}\text { Cantillo-Negrete } \\
\text { et al., 2019* }\end{array}$ & Ischemic & Subacute & MA (10) & $\underset{(10)}{\text { Standard therapy }}$ & $\begin{array}{c}4 \mathrm{w} \\
(3 \mathrm{~d} / \mathrm{w}, 30 \mathrm{~min} / \mathrm{d})\end{array}$ & $\begin{array}{l}\text { FMA-UE, ARAT, } \\
\text { Dynamometry, } \\
\text { TMS, qEEG }\end{array}$ & $\begin{array}{c}\Delta \mathrm{BCI}=2.4 \\
\Delta \mathrm{Control}=3.5\end{array}$ \\
\hline \multicolumn{8}{|c|}{ Neuromuscular Electrical Stimulation (NMES) } \\
\hline $\begin{array}{l}\mathrm{Li} \\
\text { et al., } 2014\end{array}$ & $\begin{array}{l}\text { Ischemic and } \\
\text { Hemorrhagic }\end{array}$ & Subacute & MI (7) & NMES only & $\begin{array}{c}8 \mathrm{w} \\
(3 \mathrm{~d} / \mathrm{w}, 60-90 \\
\mathrm{min} / \mathrm{d})\end{array}$ & FMA-UE, ARAT & $\begin{array}{c}\Delta \mathrm{BCI}=12.7 \\
\Delta \mathrm{Control}=6.7\end{array}$ \\
\hline $\begin{array}{l}\text { Kim } \\
\text { et al., } 2016\end{array}$ & $\begin{array}{l}\text { Ischemic and } \\
\text { Hemorrhagic }\end{array}$ & Chronic & MI (15) & $\underset{(15)}{\text { Standard therapy }}$ & $\begin{array}{c}4 \mathrm{w} \\
(5 \mathrm{~d} / \mathrm{w}, 30 \mathrm{~min} / \mathrm{d})\end{array}$ & $\begin{array}{c}\text { FMA-UE, } \\
\text { MAL, MBI, ROM }\end{array}$ & $\begin{array}{c}\Delta \mathrm{BCI}=7.9 \\
\Delta \mathrm{Control}=2.9\end{array}$ \\
\hline $\begin{array}{l}\text { Biasiucci } \\
\text { et al., } 2018\end{array}$ & $\begin{array}{l}\text { Ischemic and } \\
\text { Hemorrhagic }\end{array}$ & Chronic & MA (14) & $\operatorname{Sham}_{(13)}$ & $\begin{array}{c}5 \mathrm{w} \\
(2 \mathrm{~d} / \mathrm{w}, 60 \mathrm{~min} / \mathrm{d})\end{array}$ & $\begin{array}{c}\text { FMA-UE, } \\
\text { MRC, MAS, ESS }\end{array}$ & $\begin{array}{c}\Delta \mathrm{BCI}=6.7 \\
\Delta \text { Control }=2.1\end{array}$ \\
\hline $\begin{array}{l}\text { Remsik } \\
\text { et al., } 2018\end{array}$ & $\begin{array}{l}\text { Ischemic and } \\
\text { Hemorrhagic }\end{array}$ & $\begin{array}{l}\text { Subacute } \\
\text { and chronic }\end{array}$ & MA (21) & No therapy & $\begin{array}{c}4-6 \mathrm{w} \\
(2-3 \mathrm{~d} / \mathrm{w}, 90 \\
\mathrm{min} / \mathrm{d})\end{array}$ & $\begin{array}{c}\text { ARAT, } \\
\text { SIS, 9HPT, } \\
\text { Dynamometry }\end{array}$ & No data \\
\hline \multicolumn{8}{|c|}{ Visual Feedback } \\
\hline $\begin{array}{l}\text { Mihara } \\
\text { et al., } 2013\end{array}$ & $\begin{array}{l}\text { Ischemic and } \\
\text { Hemorrhagic }\end{array}$ & Subacute & NIRS-MI (10) & Sham & $\begin{array}{c}2 \mathrm{w} \\
(3 \mathrm{~d} / \mathrm{w}, 20 \mathrm{~min} / \mathrm{d})\end{array}$ & $\begin{array}{l}\text { FMA-UE, ARAT, } \\
\text { MAL, KVIQ-10 }\end{array}$ & $\begin{array}{c}\Delta \mathrm{BCI}=5.0 \\
\Delta \text { Control }=2.3\end{array}$ \\
\hline $\begin{array}{l}\text { Rayegani } \\
\text { et al., } 2014\end{array}$ & No data & Subacute & MI (10) & $\begin{array}{c}\text { Standard Therapy } \\
(10) \\
\text { Standard } \\
\text { Therapy+EMG } \\
(10)\end{array}$ & $\begin{array}{c}2 \mathrm{w} \\
(5 \mathrm{~d} / \mathrm{w}, 60 \mathrm{~min} / \mathrm{d})\end{array}$ & JHFT & No data \\
\hline $\begin{array}{l}\text { Pichiorri } \\
\text { et al., } 2015\end{array}$ & $\begin{array}{l}\text { Ischemic and } \\
\text { Hemorrhagic }\end{array}$ & Subacute & MI (14) & $\underset{(14)}{\text { MI only }}$ & $\begin{array}{c}4 \mathrm{w} \\
(3 \mathrm{~d} / \mathrm{w}, 30 \mathrm{~min} / \mathrm{d})\end{array}$ & $\begin{array}{c}\text { FMA-UE, } \\
\text { MRC, NIHSS }\end{array}$ & $\begin{array}{c}\Delta \mathrm{BCI}=44.0 \\
\Delta \text { Control }=19.8^{*}\end{array}$ \\
\hline
\end{tabular}

Baseline and post-therapy upper limb motor assessments of the groups of the included studies (Figure 2A), implied that all the experimental groups achieved in average an increase in upper limb motor function after the BCI intervention. Higher motor function was also observed in all except one of the control groups. In addition, as implied by the FMA-UE taken from Table 1, median recovery for all the studies was 6.6 points of the scale. Since the clinically minimal important difference has been set at a gain of 5.25 points of the FMA-UE ${ }^{[73]}$, it can be inferred that a tendency towards a significant increase in upper limb motor recovery, is suggested by the reviewed literature. This provides evidence that patients are being benefited from their participation in studies aimed to evaluate the effectiveness of BCI for upper limb motor rehabili- 
tation, even if they participate in the control groups of these studies. Therefore, stroke patient's inclusion within these studies could increase their possibilities of achieving some degree of recovery. This could aid research groups that aim to assess BCI for upper limb rehabilitation to provide evidence that such intervention is likely to provide at least some motor recovery, and thus increase patients recruitment since low recruitment rates have been reported to reduce advancement in the field ${ }^{[53]}$ [74].

Regarding differences between experimental and control groups, most studies reported higher recovery with the BCI intervention compared to the control group $(n=7)$. The other reviewed studies reported lower mean recovery compared to controls $(n=3)$, or the same mean recovery $(n=1)$. However, only two of the studies that reported higher recovery with the BCI, stated that this recovery was statistically significantly higher compared to the control group ${ }^{[6] 1] 63]}$. Therefore, the limited evidence that has been presented in the literature suggests that $\mathrm{BCI}$ interventions are likely comparable to other interventions such as therapy with robotic assistive devices and NMES for stroke upper limb rehabilitation. However, more studies are needed in order to assess if it is possible that a BCI intervention can be a more effective rehabilitation than other type of interventions.

Clinical characteristics of stroke within the revised studies, showed that most studies included patients with both ischemic and hemorrhagic stroke. This could increase the variability of the reported upper function outcomes, since it is known that hemorrhagic strokes present faster recovery rates compared to ischemic ${ }^{[75]}$. In addition, most of the reviewed studies $(n=7)$ recruited stroke patients in the chronic stage of the disease, while fewer recruited subacute $(n=5)$, and a mixed of subacute and chronic stroke patients $(n=2)$. This is of relevance since it has been stated that neuroplasticity processes are more likely to be elicited during subacute compared to chronic stages of stroke ${ }^{[76]}$, therefore, the effects of a BCI system in subacute and chronic stroke stages could be different. Therefore, a proposed strategy for reducing stroke patients' upper limb rehabilitation outcomes variability in BCI studies, could be based in performing studies which only involve either ischemic or hemorrhagic, and either subacute or chronic stroke patients. Or alternatively, if the sample is large, then it is feasible to perform a separate analysis on the results from patients with different etiologies and time since stroke onset.

Intervention duration time could also affect motor upper limb outcomes among the reviewed studies, since although most of the experimental designs used a fixed intervention period $(n=12)$, their duration was heterogenous. For example, the study with the highest intervention time was reported by $\mathrm{Li}$ et al. with an 8-week duration [63], while Kasashima-Shindo et al.[51], Frolov et al. [67], Mihara et al. ${ }^{[60]}$, and Rayegani et al. interventions' periods were of 2 weeks. Also, the number of BCI interventions for each week and duration of each therapy varied greatly across studies. Therefore, more evidence is still needed of the effects of BCI intervention time periods and motor recovery in stroke, since the relationship between treatment dosage and stroke recovery is still unknown 546 as stated by Cassidy et al. [77].

Finally, few of the reviewed studies complemented clinical assessments with physiological measurements such as qEEG $(n=4)$. These measurements could aid to understand the neural plasticity mechanisms associated with upper limb motor recovery during an intervention with a BCI system. For example, several studies have provided evidence that cortical activations measured with qEEG above motor and non-motor regions, are associated with motor recovery [52] [78] [77] ${ }^{[80] . ~ f M R I, ~ a n ~ i m a g i n g ~ m o d a l i t y ~ w i t h ~ a ~ g r e a t e r ~ s p a t i a l ~}$ resolution compared to EEG, has also been used for hypothesizing a relationship between clearly identi- 
fied cortical and subcortical regions with motor recovery ${ }^{[81]}$. Also, Transcranial Magnetic Stimulation (TMS) could be used to evaluate corticospinal tract integrity and cortical excitability of stroke patients during BCI interventions, since these variables have also been associated with motor recovery ${ }^{[82]}$. Therefore, if future studies include these physiological measurements, BCI for upper limb stroke rehabilitation, could be designed by taking into account how to increase neuroplasticity during the intervention.

\section{CONCLUSIONS}

Assessment of BCI for upper limb stroke rehabilitation has been reported in a low number of patients in order to draw conclusions regarding its effectiveness compared with standard or other experimental treatments. Furthermore, design features such as type of feedback, etiology of stroke and intervention duration, differ between studies. Therefore, a larger number of studies and patient engagement is still needed for assessing the clinical potential of BCI in upper limb stroke rehabilitation. Also, trends within the field were identified, such as the spearheading of robotic devices as feedback, MI or MA used as BCI paradigms, and that it is likely that patients achieve some degree of recovery during a BCI experimental therapy. In addition, increasing the coordination between research groups in order to reduce variability within studies designs and enhancing the engagement of areas with low participation in the research field, could aid in establishing the role of BCI systems for upper limb stroke rehabilitation. If the clinical role of BCI is established, then more and longer sessions of therapies could be provided for patients. In addition, since these systems could be automatized, less intervention of physiotherapists would be needed to provide therapies, which could aid to tackle the lack of personnel needed to treat stroke patients, expected by the WHO in the forthcoming decades ${ }^{[83]}$. Particularly, Mexico could be greatly benefited by a complementary therapy for upper limb stroke rehabilitation, which demand is also expected to increase as population ages.

\section{ACKNOWLEDGMENTS}

Authors would like to thank to Karina V. Gonzales Salazar for her help in conceiving the artwork of the study. 


\section{REFERENCES}

[1] Wolpaw JR, Birbaumer N, McFarland DJ, Pfurtscheller G, Vaughan TM. Brain-computer interfaces for communication and control. Clin Neurophysiol. 2002;113(6):767-91. https://doi.org/10.1016/S1388-2457(02)00057-3

[2] Kerous B, Skola F, Liarokapis F. EEG-based BCI and video games: a progress report. Virtual Real. 2018;22(2):119-35. 10.1007/s10055017-0328-x

[3] Morin C. Neuromarketing: The New Science of Consumer Behavior. Society. 2011;48(2):131-5. 10.1007/s12115-010-9408-1

[4] Gao X, Xu D, Cheng M, Gao S. A BCI-based environmental controller for the motion- disabled. IEEE Trans Neural Syst Rehabil Eng. 2003;11(2):137-40.

[5] Pichiorri F, Petti M, Caschera S, Astolfi L, Cincotti F, Mattia D. An EEG index of sensorimotor interhemispheric coupling after unilateral stroke: clinical and neurophysiological study. Eur J Neurosci. 2018;47(2):158-63. 10.1111/ejn.13797

[6] Rohm M, Schneiders M, Müller C, Kreilinger A, Kaiser V, MüllerPutz GR, et al. Hybrid brain-computer interfaces and hybrid neuroprostheses for restoration of upper limb functions in individuals with high-level spinal cord injury. Artif Intell Med. 2013;59(2):133- 42. https://doi.org/10.1016/j.artmed.2013.07.004

[7] Ramos-Murguialday A, Broetz D, Rea M, Läer L, Yilmaz Ö, Brasil $\mathrm{FL}$, et al. Brain-machine interface in chronic stroke rehabilitation: A controlled study. Ann Neurol. 2013;74(1):100-8.

[8] Cervera MA, Soekadar SR, Ushiba J, Millán J del R, Liu M, Birbaumer N, et al. Brain- computer interfaces for post-stroke motor rehabilitation: a meta-analysis. Vol. 5, Annals of Clinical and Translational Neurology. Wiley-Blackwell; 2018. p. 651-63.

[9] J. BE, Paul M, Alvaro A, S. BM, W. CC, P. CA, et al. Heart Disease and Stroke Statistics-2019 Update: A Report From the American Heart Association. Circulation. 2019;139(10):e56-528. 10.1161/CIR.0000000000000659

[10] Monge-Pereira E, Ibañez-Pereda J, Alguacil-Diego IM, Serrano JI, Spottorno-Rubio MP, Molina-Rueda F. Use of

Electroencephalography Brain-Computer Interface Systems as a Rehabilitative Approach For Upper Limb Function After a Stroke: A Systematic Review. Vol. 9, PM and R. Elsevier Inc.; 2017. p. 918-32.

[11] López-Larraz E, Sarasola-Sanz A, Irastorza-Landa N, Birbaumer N, Ramos-Murguialday A. Brain-machine interfaces for rehabilitation in stroke: A review. NeuroRehabilitation. 2018;43(1):77-97.

[12] Bath PM, Lees KR. Acute stroke. West J Med. 2000;173(3):209-12.

[13] Katzan I. Acute ischemic Stroke. In: Babak T, Cummings J, editor. Neuro-Geriatrics. 2017. p. 49-66.

[14] Marquez-Romero JM, Arauz A, Góngora-Rivera F, Barinagarrementeria F, Cantú C. The burden of stroke in México. Int J Stroke. 2015;10(2):251-2.

[15] Ang KK, Guan C, Chua KSG, Ang BT, Kuah C, Wang C, et al. A clinical study of motor imagery-based brain-computer interface for upper limb robotic rehabilitation. In: 2009 Annual International Conference of the IEEE Engineering in Medicine and Biology Society. 2009. p. 5981-4.

[16] Winstein CJ, Stein J, Arena R, Bates B, Cherney LR, Cramer SC, et al. Guidelines for Adult Stroke Rehabilitation and Recovery. Stroke. 2016;47(6):e98-169.
[17] Bruce D. Rehabilitation after Stroke. N Engl J Med. 2005;352(16):1677-84.

[18] Bertani R, Melegari C, De Cola MC, Bramanti A, Bramanti P, Calabrò RS. Effects of robot-assisted upper limb rehabilitation in stroke patients: a systematic review with meta-analysis. Neurol Sci. 2017;38(9):1561-9.

[19] Mathiowetz V, Weber K, Kashman N, Volland G. Adult Norms for the Nine Hole Peg Test of Finger Dexterity. Occup Ther J Res. 1985;5(1):24-38. 10.1177/153944928500500102

[20] Hogan N, Krebs HI, Charnnarong J, Srikrishna P, Sharon A. MIT MANUS: A workstation for manual therapy and training I. In: 1992 Proceedings IEEE International Workshop on Robot and Human Communication, ROMAN 1992. 1992. p. 161-5.

[21] Sale P, Mazzoleni S, Lombardi V, Galafate D, Massimiani MP, Posteraro F, et al. Recovery of hand function with robot-assisted therapy in acute stroke patients. Int J Rehabil Res. 2014;37(3):23642. 10.1097/MRR.0000000000000059

[22] Colomer C, Baldoví A, Torromé S, Navarro MD, Moliner B, Ferri J, et al. Efficacy of Armeo ${ }^{\circledR}$ Spring during the chronic phase of stroke. Study in mild to moderate cases of hemiparesis. Neurol (English Ed. 2013;28(5):261-7. https://doi.org/10.1016/j.nrleng.2012.04.017

[23] Meyer Assessment of motor recovery after stroke: a critical review of its measurements properties. Neurorehabil Neural Repair. 2002;16(3):232-40.

[24] Lang CE, Wagner JM, Dromerick AW, Edwards DF. Measurement of Upper- Extremity Function Early After Stroke: Properties of the Action Research Arm Test. Arch Phys Med Rehabil. 2006;87(12):1605- 10

[25] Rabadi MH, Rabadi FM. Comparison of the Action Research Arm Test and the Fugl-Meyer Assessment as Measures of UpperExtremity Motor Weakness After Stroke. Arch Phys Med Rehabil. 2006;87(7):962-6. https://doi.org/10.1016/j.apmr.2006.02.036

[26] Crispin J, Ray F, Helen C, Michele P. The Stroke Impact Scale. Stroke. 2013;44(9):2532- 5. 10.1161/STROKEAHA.113.001847

[27] Hantson L, Weerdt D, Keyser, J, Diener, HC, Franke, C, Palm, R, Van-Orshoven, M, Schoonderwalt H, Klippel, N, Herroelen, L, Feys H. The European Stroke Scale. Stroke. 1994;25(11):2215-9.

[28] Turner-Stokes L. Goal attainment scaling (GAS) in rehabilitation: a practical guide. Clin Rehabil. 2009;23(4):362-70. $10.1177 / 0269215508101742$

[29] Taub, E, Miller, NE, Novack TA, Cook EW, Flemming WC, Nepomuceno, CS, Connel, JS, Crago J. Technique to improve chronic motor deficit after stroke. Arch Phys Med Rehabil. 1993;74(4):347-54.

[30] Poole JL, Whitney SL. Motor assessment scale for stroke patients: concurrent validity and interrater reliability. Arch Phys Med Rehabil. 1988;69(3 Pt 1):195-7.

[31] Tsuji T, Liu M, Sonoda S, Domen K, Chino N. The stroke impairment assessment set: Its internal consistency and predictive validity. Arch Phys Med Rehabil. 2000;81(7):863-8. https://doi.org/10.1053/apmr.2000.6275

[32] Collin C, Wade DT, Davies S, Horne V. The Barthel ADL Index: A reliability study. Int Disabil Stud. 1988;10(2):61-3. $10.3109 / 09638288809164103$ 
[33] Vanhoutte EK, Faber CG, van Nes SI, Jacobs BC, van Doorn PA, van Koningsveld R, et al. Modifying the Medical Research Council grading system through Rasch analyses. Brain. 2011/12/20. 2012;135(Pt 5):1639-49. 10.1093/brain/awr318

[34] Rider B, Linden C. Comparison of standardized and nonstandardized administration of the Jebsen Hand Function test. J Hand Ther. 1988;1(3):121-3. https://doi.org/10.1016/S0894-1130(88)80036-X

[35] Patrick L. Using the National Institutes of Health Stroke Scale. Stroke. 2017;48(2):513-9. 10.1161/STROKEAHA.116.015434

[36] Pfurtscheller G, da Silva FHL. Event-related EEG/MEG synchronization and desynchronization: basic principles. Clin Neurophysiol. 1999;110(11):1842-57. https://doi.org/10.1016/S1388-2457(99)00141-8

[37] Rotenberg A, Horvath JC P-LA. Transcranial Magnetic Stimulation”. Humana Press, New York. 2014. 32. Hannah L, et al. "Clinical Assessment of Hand Motor Performance After Acquired Brain Injury With Dynamic Computerized Hand Dynamometry: Construct, Concurrent, and Predictive Validity. New York: HUMANA PRESS; 2014.

[38] Mellinger J, Schalk G, Braun C, Preissl H, Rosenstiel W, Birbaumer $\mathrm{N}$, et al. An MEG-based brain-computer interface (BCI). Neuroimage. 2007/03/27. 2007;36(3):581-93. 10.1016/j.neuroimage.2007.03.019

[39] Coyle SM, Ward TE, Markham CM. Brain- computer interface using a simplified functional near-infrared spectroscopy system. J Neural Eng. 2007;4(3):219-26. 10.1088/1741-2560/4/3/007

[40] Leuthardt EC, Miller KJ, Schalk G, Rao RPN, Ojemann JG. Electrocorticography-based brain computer Interface-the seattle experience. IEEE Trans Neural Syst Rehabil Eng. 2006;14(2):194-8.

[41] Williams JJ, Tien RN, Inoue Y, Schwartz AB. Idle state classification using spiking activity and local field potentials in a brain computer interface. In: 2016 38th Annual International Conference of the IEEE Engineering in Medicine and Biology Society (EMBC). 2016. p. 1572-5.

[42] Pfurtscheller G, Neuper C. Motor imagery and direct braincomputer communication. Proc IEEE. 2001;89(7):1123-34. $10.1109 / 5.939829$

[43] Donoghue JP, Nurmikko A, Friehs G, Black M. Chapter 63 Development of neuromotor prostheses for humans. In: Hallett M, Phillips LH, Schomer DL, Massey JMBT-S to CN, editors. Advances in Clinical Neurophysiology. Elsevier; 2004. p. 592-606. https://doi.org/10.1016/S1567- 424X(09)70399-X

[44] Blankertz B, Tomioka R, Lemm S, Kawanabe M, Müller K-R. Optimizing Spatial Filters for Robust EEG Single-Trial Analysis [ Revealing tricks of the trade ] [ IEEE SIGNAL PROCESSING MAGAZINE [41] JANUARY 2008. IEEE Signal Process Mag. 2008;25(1):41-56.

[45] Ang KK, Chin ZY, Wang C, Guan C, Zhang H. Filter Bank Common Spatial Pattern Algorithm on BCI Competition IV Datasets 2a and 2b. Front Neurosci. 2012;6:39. 10.3389/fnins.2012.00039

[46] Carino-Escobar RI, Cantillo-Negrete J, Gutierrez-Martinez J, Vazquez RA. Classification of motor imagery electroencephalography signals using spiking neurons with different input encoding strategies. Neural Comput Appl. $2018 ; 30(4)$.
[47] Alonso-Valerdi LM, Salido-Ruiz RA, Ramirez-Mendoza RA. Motor imagery based brain-computer interfaces: An emerging technology to rehabilitate motor deficits. Neuropsychologia. 2015;79:354-63. https://doi.org/10.1016/i.neuropsychologia.201 5.09.012

[48] Kraeutner S, Gionfriddo A, Bardouille T, Boe S. Motor imagerybased brain activity parallels that of motor execution: Evidence from magnetic source imaging of cortical oscillations. Brain Res. 2014;1588:81-91. https://doi.org/10.1016/j.brainres.2014.09.001

[49] Carrillo-de-la-Peña MT, Galdo-Álvarez S, Lastra-Barreira C. Equivalent is not equal: Primary motor cortex (MI) activation during motor imagery and execution of sequential movements. Brain Res. 2008;1226:134-43. https://doi.org/10.1016/j.brainres.2008.05.089

[50] Malouin F, Richards, CL, Jackson, PL, Lafleur, MF, Durand, A, Doyon J. The Kinesthetic and Visual Imagery Questionnaire (KVIQ) for assessing motor imagery in persons with physical disabilities: a realiability and construct validity study. J Neurol Phys Ther. 2007;31(1):20-9.

[51] Kasashima-Shindo Y, Fujiwara T, Ushiba J, Matsushika Y, Kamatani $\mathrm{D}$, Oto $\mathrm{M}$, et al. Brain-computer interface training combined with transcranial direct current stimulation in patients with chronic severe hemiparesis: Proof of concept study. J Rehabil Med. 2015;47(4):318-24.

[52] Carino-Escobar RI, Carrillo-Mora P, Valdés- Cristerna R, RodriguezBarragan MA, Hernandez-Arenas C, Quinzaños-Fresnedo J, et al. Longitudinal Analysis of Stroke Patients' Brain Rhythms during an Intervention with a Brain-Computer Interface. Neural Plast. 2019;

[53] Ang KK, Guan C, Phua KS, Wang C, Zhou L, Tang KY, et al. Braincomputer interface-based robotic end effector system for wrist and hand rehabilitation: results of a three-armed randomized controlled trial for chronic stroke. Front Neuroeng. 2014;7. 10.3389/fneng. 2014.00030

[54] Ang KK, Chua KSG, Phua KS, Wang C, Chin ZY, Kuah CWK, et al. A Randomized Controlled Trial of EEG-Based Motor Imagery BrainComputer Interface Robotic Rehabilitation for Stroke. Clin EEG Neurosci. 2015;46(4):310-20.

[55] Várkuti B, Guan C, Pan Y, Phua KS, Ang KK, Kuah CWK, et al. Resting State Changes in Functional Connectivity Correlate With Movement Recovery for BCI and Robot- Assisted Upper-Extremity Training After Stroke. Neurorehabil Neural Repair. 2012;27(1):5362. 10.1177/1545968312445910

[56] Knutson JS, Fu MJ, Sheffler LR, Chae J. Neuromuscular Electrical Stimulation for Motor Restoration in Hemiplegia. Phys Med Rehabil Clin N Am. 2015;26(4):729-45.

https://doi.org/10.1016/j.pmr.2015.06.002

[57] Kim T, Kim S, Lee B. Effects of Action Observational Training Plus Brain-Computer Interface-Based Functional Electrical Stimulation on Paretic Arm Motor Recovery in Patient with Stroke: A Randomized Controlled Trial. Occup Ther Int. 2016;23(1):39-47. $\underline{10.1002 / o t i .1403}$

[58] Biasiucci A, Leeb R, Iturrate I, Perdikis S, Al- Khodairy A, Corbet T, et al. Brain-actuated functional electrical stimulation elicits lasting arm motor recovery after stroke. Nat Commun. 2018;9(1):2421. 10.1038/s41467-018-04673-z

[59] Alimardani M, Nishio S, Ishiguro H. The Importance of Visual Feedback Design in BCIs; from Embodiment to Motor Imagery Learning. PLoS One. 2016;11(9):e0161945. 
[60] Masahito M, Noriaki H, Megumi H, Hajime Y, Teiji K, Taro H, et al. Near-infrared Spectroscopy-mediated Neurofeedback Enhances Efficacy of Motor Imagery-based Training in Poststroke Victims. Stroke. 2013;44(4):1091-8. 10.1161/STROKEAHA.111.674507

[61] Pichiorri F, Morone G, Petti M, Toppi J, Pisotta I, Molinari M, et al. Brain-computer interface boosts motor imagery practice during stroke recovery. Ann Neurol. 2015;77(5):851- 65.

10.1002/ana.24390

[62] Carino-Escobar RI, Carrillo-Mora P, Valdés- Cristerna R, RodriguezBarragan MA, Hernandez-Arenas C, Quinzaños-Fresnedo J, et al. Longitudinal Analysis of Stroke Patients' Brain Rhythms during an Intervention with a Brain-Computer Interface. Neural Plast. 2019; $10.1155 / 2019 / 7084618$

[63] LiM,LiuY,WuY,LiuS,JiaJ,ZhangL. Neurophysiological substrates of stroke patients with motor imagery-based brain- computer interface training. Int J Neurosci. 2014;124(6):403-15. $10.3109 / 00207454.2013 .850082$

[64] Remsik AB, Dodd K, Williams Jr L, Thoma J, Jacobson T, Allen JD, et al. Behavioral Outcomes Following Brain-Computer Interface Intervention for Upper Extremity Rehabilitation in Stroke: A Randomized Controlled Trial. Front Neurosci. 2018;12:752. 10.3389/fnins.2018.00752

[65] Rayegani SM, Raeissadat SA, Sedighipour L, Mohammad Rezazadeh I, Bahrami MH, Eliaspour D, et al. Effect of Neurofeedback and Electromyographic-Biofeedback Therapy on Improving Hand Function in Stroke Patients. Top Stroke Rehabil. 2014;21(2):137- 51. 10.1310/tsr2102-137

[66] Ono T, Shindo K, Kawashima K, Ota N, Ito M, Ota T, et al. Braincomputer interface with somatosensory feedback improves functional recovery from severe hemiplegia due to chronic stroke. Front Neuroeng. 2014;7.

[67] Frolov AA, Mokienko O, Lyukmanov R, Biryukova E, Kotov S, Turbina L, et al. Post- stroke rehabilitation training with a motorimagery-based brain-computer interface (BCI)- controlled hand exoskeleton: A randomized controlled multicenter trial. Front Neurosci. 2017;11(JUL).

[68] Küçükdeveci AA, Stibrant Sunnerhagen K, Golyk V, Delarque A, Ivanova G, Zampolini M, et al. Evidence-based position paper on Physical and Rehabilitation Medicine professional practice for persons with stroke The European PRM Position (UEMS PRM Section). Eur J Phys Rehabil Med. 2018;54(6):957-70.

[69] Kwakkel G, Veerbeek JM, van Wegen EEH, Wolf SL. Constraintinduced movement therapy after stroke. Lancet Neurol. 2015;14(2):224-34. 10.1016/S1474- 4422(14)70160-7

[70] Pérez-Cruzado D, Merchán-Baeza JA, González-Sánchez M, Cuesta-Vargas AI. Systematic review of mirror therapy compared with conventional rehabilitation in upper extremity function in stroke survivors. Aust Occup Ther J. 2017;64(2):91-112. 10.1111/1440-1630.12342

[71] Howlett OA, Lannin NA, Ada L, McKinstry C. Functional Electrical Stimulation Improves Activity After Stroke: A Systematic Review With Meta-Analysis. Arch Phys Med Rehabil. 2015;96(5):934-43. https://doi.org/10.1016/j.apmr.2015.01.013
[72] Cantillo-Negrete J, Carino-Escobar RI, Carrillo-Mora P, BarrazaMadrigal JA, Arias- Carrión O. Robotic orthosis compared to virtual hand for Brain-Computer Interface feedback. Biocybern Biomed Eng. 2019;39(2):263-72.

[73] Page SJ, Fulk GD, Boyne P. Clinically Important Differences for the Upper-Extremity Fugl-Meyer Scale in People With Minimal to Moderate Impairment Due to Chronic Stroke. Phys Ther. 2012;92(6):791-8. 10.2522/ptj.20110009

[74] Birchenall J, Térémetz M, Roca P, Lamy J-C, Oppenheim C, Maier $\mathrm{MA}$, et al. Individual recovery profiles of manual dexterity, and relation to corticospinal lesion load and excitability after stroke -a longitudinal pilot study. Neurophysiol Clin. 2019;49(2):149-64. https://doi.org/10.1016/j.neucli.2018.10.065

[75] Kelly PJ, Furie KL, Shafqat S, Rallis N, Chang Y, Stein J. Functional recovery following rehabilitation after hemorrhagic and ischemic stroke11No commercial party having a direct financial interest in the results of the research supporting this article has or will confer a benefit on the authors or on any organiz. Arch Phys Med Rehabil. 2003;84(7):968-72. https://doi.org/10.1016/50003-9993(03)00040-6

[76] Han-Young J. Rehabilitation in Subacute and Chronic Stage After Stroke. In: Seung-Hoon L, editor. Stroke Revisited: Diagnosis and Treatment of Ischemic Stroke. 1st ed. Springer; 2017. p. 352-60.

[77] Cassidy JM, Cramer SC. Spontaneous and Therapeutic-Induced Mechanisms of Functional Recovery After Stroke. Transl Stroke Res. 2017;8(1):33-46.

[78] Gandolfi M, Formaggio E, Geroin C, Storti SF, Galazzo IB, Bortolami M, et al. Quantification of Upper Limb Motor Recovery and EEG Power Changes after Robot-Assisted Bilateral Arm Training in Chronic Stroke Patients : A Prospective Pilot Study. 2018;2018.

[79] Rondina, JM, Park, CH, Ward N. Brain regions important for recovery after severe post-stroke upper limb paresis. J Nuerology, Neurosurg Psychiatry. 2017;88(9):737-43.

[80] Kaiser V, Daly I, Pichiorri F, Mattia D, Müller-Putz G, Neuper C. Relationship Between Electrical Brain Responses to Motor Imagery and Motor Impairment in Stroke. Stroke. 2012;43(10):2735-40. 10.1161/STROKEAHA.112.665489

[81] Chang-hyun P, Hyuk CW, Hoon OS, Tae KS, Young BO, Alvaro P-L, et al. Longitudinal Changes of Resting-State Functional Connectivity During Motor Recovery After Stroke. Stroke. 2011;42(5):1357-62. 10.1161/STROKEAHA.110.596155

[82] Shiner CT, Tang H, Johnson BW, McNulty PA. Cortical beta oscillations and motor thresholds differ across the spectrum of post- stroke motor impairment, a preliminary MEG and TMS study. Brain Res. 2015;1629:26-37. https://doi.org/10.1016/j. brainres.2015.09.037

[83] Krug E, Cieza A. Strengthening health systems to provide rehabilitation services. Bull World Health Organ. 2017;95(3):167. 